\begin{abstract}
Background: In aromatherapy, essential oils are used as anti-inflammatory remedies, but experimental studies on their action mechanisms are very limited. Aims: To assess their anti-inflammatory activities, effects of essential oils on neutrophil activation were examined in vitro.

Methods: Neutrophil activation was measured by tumor necrosis factor-alpha (TNF- $\alpha$ )-induced adherence reaction of human peripheral neutrophils.

Results: All essential oils tested at $0.1 \%$ concentration suppressed TNF- $\alpha$-induced neutrophil adherence, and, in particular, lemongrass, geranium and spearmint oils clearly lowered the reaction even at $0.0125 \%$. Similar inhibitory activities for the neutrophil adherence were obtained by their major constituent terpenoids: citral, geraniol, citronellol and carvone. In contrast, very popular essential oils, tea tree oil and lavender oil, did not display the inhibitory activity at the concentration.

Conclusion: Thus, some essential oils used as antiinflammatory remedies suppress neutrophil activation by TNF- $\alpha$ at a low concentration (0.0125-0.025\%) in vitro.
\end{abstract}

\section{Suppression of tumor necrosis factor-alpha-induced neutrophil adherence responses by essential oils}

\author{
Shigeru Abe ${ }^{1, C A}$, Naho Maruyama ${ }^{1}$, \\ Kazumi Hayama ${ }^{1,2}$, Hiroko Ishibashi", \\ Shigeharu Inoue ${ }^{1}$, Haruyuki Oshima ${ }^{2}$ and \\ Hideyo Yamaguchi ${ }^{1}$
}

${ }^{1}$ Teikyo University Institute of Medical Mycology, 359 Otsuka, Hachioji, Tokyo 192-0395, Japan and ${ }^{2}$ Department of Bioengineering, Faculty of Technology, Teikyo University, 1-1, Toyosato-dai, Utsunomiya, Tochigi 320-0003, Japan

\section{Introduction}

Aromatherapy is a folk medicine originated from the traditional therapeutic use of essential oils, and in recent years it has attracted attention as one of the alternative medicines especially in the modern medical field. The essential oils used in aromatherapy are believed to have various pharmacological functions such as antimicrobial, sedative and anti-inflammatory activities, but these activities are mainly recognized through clinical experience and have been little elucidated experimentally. Especially, the anti-inflammatory activity of these oils and the mechanisms underlying their anti-inflammatory actions remain to be clarified.

Recently several investigators found that tea tree $\mathrm{oil}^{1-3}$ and lavender oil ${ }^{4}$ suppressed allergic symptoms through the suppression of histamine release $e^{5,6}$ and cytokine production. ${ }^{7}$ It is known that in inflammatory response, neutrophils accumulate around the lesional area infected by microbes, and play a major role in host defense responses. Activated neutrophils, on the contrary, may induce excessive inflammatory responses and damage tissues around the area and make the symptoms worse by the secretion of superoxides, proteases and other antibacterial substances. Although these neutrophils are well recognized to play these major regulatory roles in inflammation, the effects of essential oils on neutrophil function have not been investigated. Neutrophil activation is known to occur through two steps, priming and triggering. ${ }^{8}$ Priming of neutrophils by inflammatory cytokines such as tumor necrosis factor-alpha (TNF- $\alpha$ ) or interleukin (IL)-8 augments their following response triggered by interaction with microbes. Yakuwa et al. ${ }^{9}$ reported that priming response of neutrophils can be experimentally estimated by a rapid and simple in vitro method using neutrophil adhesion to plastic culture plates.

In the present study, we investigated the effects of the essential oils, noted in various books ${ }^{10-13}$ as a remedy for inflammatory symptoms, against neutrophil adherence response in order to assess the modulatory activity of the oils to neutrophils in inflammatory reaction. Here we found that less than $0.025 \%$ solution of several essential oils suppressed the adherence reaction of neutrophils induced by TNF- $\alpha$ stimulation. ${ }^{9,14}$ 
Table 1. Essential oils, main constituents, their sources and manufacturer

\begin{tabular}{|c|c|c|c|c|}
\hline Essential oils & Latin name & Main constituents & Source & References \\
\hline Lemongrass & Cymbop & Citra & Sanoflore (Fr & 11,12 \\
\hline Thyme red & Thymus & Thymol & ermany) & 13 \\
\hline $\mathrm{P}$ & Pogostemon cablin & $P$ & Sermany) & 11,12 \\
\hline Spearmint & Mentha spicata & Carvone & Sanoflore (France) & 11,12 \\
\hline Eucalyptus & Eucalyptus glogulus & 1,8 -cineole & LA FLORINA (Germany) & 10 \\
\hline Tea tree & Melaleuca alternifolia & Terpinen-4-ol & lore (France) & 11,12 \\
\hline True Lavender & Lavandula angustifolia & Linalool & Sanoflore (France) & $10-12$ \\
\hline Geranium Bourbon & Perargonium asperum & Geraniol, beta- & Sanoflore (France) & $10-12$ \\
\hline er & Juniperus & Alph & San & $10-12$ \\
\hline German chamomile & Matricaria chamomilla & Camazulene & Meadows (UK) & $10-12$ \\
\hline
\end{tabular}

\section{Materials and methods}

\section{Essential oils}

The essential oils used are presented in Table 1 with their sources and main constituents. Table 1 also presents literature references that show clinical use related to inflammatory symptoms. Essential oils were diluted to $50 \%$ solution by dimethyl sulfoxide (DMSO), then to $0.4 \%$ by RPMI 1640 medium containing $10 \%$ fetal calf serum (complete medium). The $0.4 \%$ solution of essential oil was further diluted using the complete medium containing $0.4 \%$ DMSO (D-medium) to $0.2 \%, 0.1 \%, 0.05 \%$, and $0.025 \%$.

\section{Agents}

Human recombinant TNF- $\alpha\left(2 \times 10^{6} \mathrm{U} / \mathrm{mg}\right.$ of protein) was donated by Asahi Chemical Industries (Tokyo, Japan) and stored at $-80^{\circ} \mathrm{C}$ until used. It was diluted to $40 \mathrm{U} / \mathrm{ml}$ using the complete medium. Escherichia coli lipopolysaccharide (LPS) (0127:B8) was purchased from Difco Lab (Detroit, MI, USA), diluted to $1 \mathrm{mg} / \mathrm{ml}$ using the complete medium and stored at $-80^{\circ} \mathrm{C}$. For experiments, the solution was diluted to $4 \mu \mathrm{g} / \mathrm{ml}$ using the complete medium. Phorbol 12-myristate 13-acetate (PMA) was purchased from Wako Pure Chemical Industries, Ltd (Osaka, Japan) and stored at $-20^{\circ} \mathrm{C}$. One milligram of PMA was dissolved in $20 \mu \mathrm{l}$ of DMSO and diluted to $2 \times 10^{-7} \mathrm{M}$ using the complete medium for experiments.

Citral was purchased from Nacalai Tesque, Inc. (Kyoto, Japan). Carvone, geraniol and linalool were purchased from Wako Pure Chemical Industries, Ltd. Terpinen-4-ol and beta-citronellol were purchased from Tokyo Kasei Kogyo Co., Ltd (Tokyo, Japan).

\section{Neutrophil preparation and adherence assay}

Human peripheral blood neutrophils were obtained as described previously by Tansho et al. ${ }^{15}$ Twenty microliters of heparinized venous blood obtained from healthy volunteers was mixed with $10 \mathrm{ml}$ of $7 \%$ dextran and allowed to stand at room temperature for $1 \mathrm{~h}$. The leukocyte-rich supernatant was centrifuged at $1900 \mathrm{rpm}$ at $20^{\circ} \mathrm{C}$ for $35 \mathrm{~min}$ on a One-step Polymorph (Accurate Chemical Scientific Corp., Westbury, NY, USA), then the neutrophil-rich layer was recovered. It was mixed with the complete medium and centrifuged at $1800 \mathrm{rpm}$ at $4^{\circ} \mathrm{C}$ for 5 min. The precipitate, consisting of more than 95\% neutrophils, was suspended to $2.0 \times 10^{6}$ cells $/ \mathrm{ml}$ by the complete medium.

The neutrophil adherence test was performed as described by Ohnishi et al. ${ }^{14}$ originally described by Yakuwa et al. ${ }^{9}$ Fifty microliters of $40 \mathrm{U} / \mathrm{ml}$ of TNF- $\alpha$ in the complete medium were poured into the wells of 96-well flat-bottom culture plates, followed by 100 $\mu \mathrm{l}$ of neutrophil suspension $\left(2.0 \times 10^{6} \mathrm{cells} / \mathrm{ml}\right)$. Then $50 \mu \mathrm{l}$ aliquots of diluted essential oil in the D-medium were added. After centrifugation at $600 \mathrm{rpm}$ for 2 min, the mixtures were incubated for $1 \mathrm{~h}$ at $37^{\circ} \mathrm{C}$ in a $5 \% \mathrm{CO}_{2}$ incubator. After the incubation, the supernatants were discarded to remove non-adherent cells, and the adherent cells were washed with saline and dried. Then the cells were stained for $15 \mathrm{~min}$ at room temperature after addition of $200 \mu \mathrm{l}$ of $0.5 \%$ crystal violet, washed three times with saline, and solubilized by the addition of $100 \mu \mathrm{l}$ of $1 \%$ sodium dodecyl sulfate. Neutrophil adherence to the plates was evaluated by measuring the absorbance of triplicate samples at $620 \mathrm{~nm}$ (OD value). The values of neutrophil adherence were relatively expressed by the ratio to those in the presence of TNF- $\alpha(10 \mathrm{U} / \mathrm{ml})$ without oils. In some experiments, instead of TNF- $\alpha$, $50 \mu \mathrm{l}$ of $4 \mu \mathrm{g} / \mathrm{ml}$ of LPS or $2 \times 10^{-7} \mathrm{M}$ of PMA was poured into the wells. All experiments were performed using neutrophils from different volunteers at least two times.

\section{Results}

\section{Effects of essential oils on TNF- $\alpha$-induced neutrophil adhesion in vitro}

The effects of 10 essential oils on adherent responses of human neutrophils induced by TNF- $\alpha$ were first examined. Human neutrophils adhered to plastic plates within $1 \mathrm{~h}$ culture when the cells were incubated in the medium with $10 \mathrm{U} / \mathrm{ml}$ of $\mathrm{TNF}-\alpha$, 
giving $0.5-1.0$ as the OD $620 \mathrm{~nm}$ value representing their adherence.

Preliminary experiments showed that the adherent activity of neutrophils cultured with TNF- $\alpha$ were strongly suppressed to below $10 \%$ of adherence percent by more than $0.1 \%$ oils (data not shown). We have confirmed that addition of DMSO (0.4\%) to the medium has no significant effects on TNF- $\alpha-$ induced neutrophil adherence (data not shown). Accordingly, the activities of essential oils at less than $0.05 \%$ were examined in detail and the results are shown in Fig. 1A-D. Lemongrass oil showed marked inhibition of neutrophil adherence at $0.00625 \%$; the inhibition was increased slightly more at $0.0125 \%$ and was saturated at $0.05 \%$. Thyme red oil did not affect the adherence at $0.00625 \%$, but gradually inhibited it dose dependently at $0.0125 \%$ and $0.025 \%$ (Fig. 1A). Geranium and spearmint oils showed potent and comparable inhibition as shown in Fig. 1B. The inhibition of lavender and tea tree oils
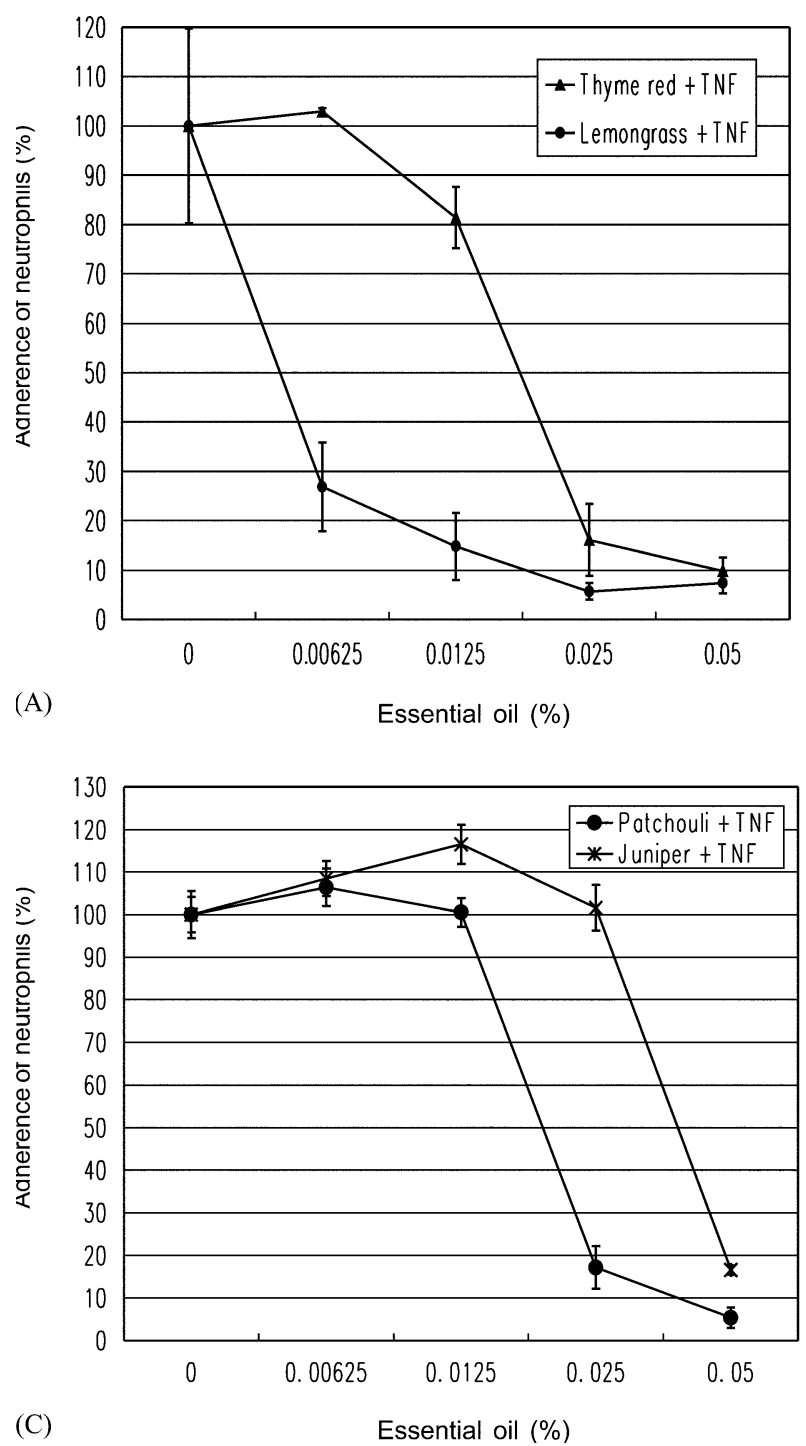

was weaker than that of geranium and spearmint (Fig. 1B). Patchouli and juniper oils (Fig. 1C) and eucalyptus and german chamomile oils (Fig. 1D) showed much weaker inhibition. Judging from the $\mathrm{IC}_{50}$ values, lemongrass oil had the strongest suppressing activity $\left(\mathrm{IC}_{50}<0.00625 \%\right)$, followed by geranium and spearmint oils $\left(\mathrm{IC}_{50}=0.013 \%\right.$ and $0.016 \%$, respectively) (Table 2). Tea tree and lavender oils showed weak suppressing activity ( $\mathrm{IC}_{50}=0.033 \%$ and $0.027 \%$, respectively), while eucalyptus oil showed no suppressing activity $\left(\mathrm{IC}_{50}>0.05 \%\right)$. These results indicate that the suppressing activities of the essential oils on TNF- $\alpha$-induced neutrophil adhesion differ.

\section{Comparison of the effects of essential oil components}

To determine which constituents of essential oils contribute the suppressing activities, we compared
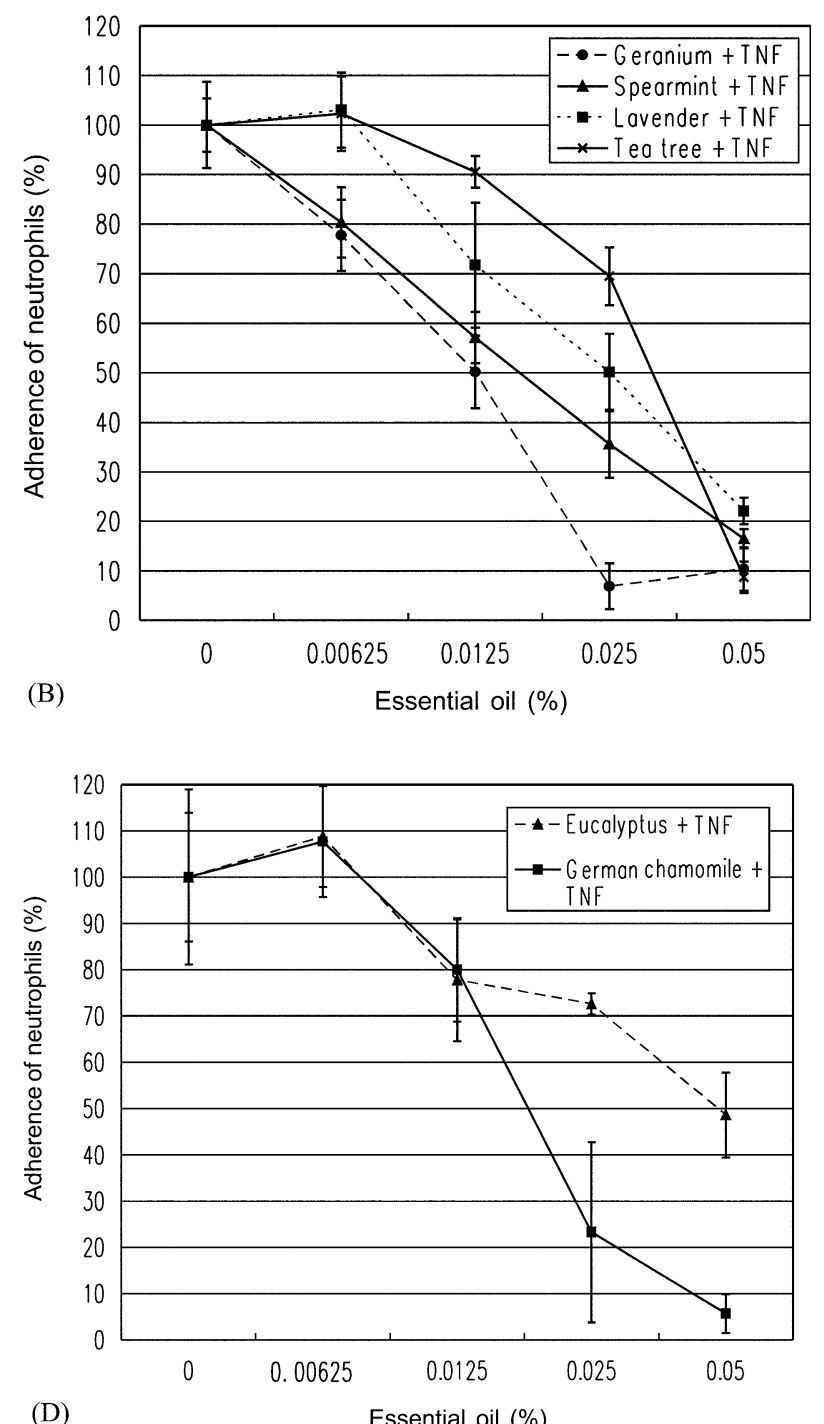

FIG. 1. Effects of essential oils on TNF--induced neutrophil adherence Human neutrophils were incubated in medium containing $10 \mathrm{U} / \mathrm{ml}$ of human TNF- and arious essential oils for $1 \mathrm{~h}$. Then neutrophils adhering to a plastic well were stained with crystal iolet, and the cells were lysed and measured photometronically. 
Table 2. Suppressive activity of essential oils to neutrophil adherence induced by TNF- $\alpha$

\begin{tabular}{lc}
\hline Essential oil & $\mathrm{IC}_{50}(\%)$ \\
\hline Lemongrass & $<0.00625$ \\
Geranium & $0.013 \pm 0.0016$ \\
Spearmint & $0.016 \pm 0.021$ \\
Thyme red & $0.019 \pm 0.0008$ \\
Patchouli & $0.020 \pm 0.0007$ \\
G.Chamomile & $0.020 \pm 0.0042$ \\
Lavender & $0.027 \pm 0.004$ \\
Tea tree & $0.033 \pm 0.0015$ \\
Juniper & $0.040 \pm 0.0006$ \\
Eucalyptus & $>0.05$
\end{tabular}

Data calculated from the results presented in Fig. 1A-D. IC ${ }_{50}$, concentration of essential oils giving $50 \%$ inhibition of neutrophil adherence.

the activities of the main constituents of each oil. The essential oils and their constituents are presented in Table 1.

Citral (a main constituent of lemongrass), geraniol (a main constituent of geranium bourbon), and $\beta$ citronellol (a main constituent of geranium bourbon), showed the strongest suppressing activity $\left(\mathrm{IC}_{50}<\right.$ $0.00625 \%$ ), followed by carvone (a main constituent of spearmint) $\left(\mathrm{IC}_{50}=0.0083 \%\right)$ (Fig. 2 and Table 3). These main constituents suppressed the adhesion at lower concentration than those of corresponding essential oils. Terpinen-4-ol and linalool, which were the main constituents of tea tree oil and true lavender oil, had only weak suppressing activities $\left(\mathrm{IC}_{50}=0.040 \%\right.$ and $0.043 \%$, respectively $)$.

\section{Effects of essential oils on LPS-induced or PMA- induced neutrophil adhesion in vitro}

The effects of essential oils on LPS-induced neutrophil adhesion are shown in Fig. $3 \mathrm{~A}$ and Table 4. Lemongrass oil $\left(\mathrm{IC}_{50}<0.00625 \%\right)$ had the strongest suppressing activity, followed by spearmint oil and geranium oil $\left(\mathrm{IC}_{50}=0.017 \%\right.$ and $0.020 \%$ respec-
Table 3. Suppressive activity of terpenoids to neutrophil adherence induced by TNF- $\alpha$

\begin{tabular}{ll}
\hline Essential oil & $\mathrm{IC}_{50}(\%)$ \\
\hline Citral & $<0.00625$ \\
Geraniol & $<0.00625$ \\
Citronelol & $<0.00625$ \\
Carvone & $0.0083 \pm 0.0007$ \\
Linalol & $0.040 \pm 0.0029$ \\
Teripinen-4-ol & $0.043 \pm 0.010$ \\
\hline
\end{tabular}

Data calculated from the results presented in Fig. 2. IC $\mathrm{C}_{50}$, concentration of terpenoids giving $50 \%$ inhibition of neutrophil adherence.

tively). Tea tree oil did not sufficiently suppress the neutrophil adhesion induced by LPS even at $0.05 \%$ of essential oil, similar to that of the TNF- $\alpha$-induced adhesion.

The effects of essential oils on PMA-induced neutrophil adhesion are also shown in Fig. 3B and Table 4. High concentrations of these oils also inhibited the PMA-induced response, but lemongrass and spearmint oils, which displayed strong suppressing activities for TNF- $\alpha$-induced adhesion, showed only limited suppression ( $\mathrm{IC}_{50}=0.018 \%$ and $>0.05 \%$, respectively). This means that some essential oils did not suppress PMA-induced neutrophil adhesion in the same manner as these for TNF- $\alpha$ induced neutrophil adhesion.

\section{Discussion}

When the activity of 10 essential oils on human neutrophil function was investigated, especially on TNF- $\alpha$-induced neutrophil adhesion to plastic plates, several of these oils had strong capability to suppress the neutrophil responses in vitro. $\mathrm{IC}_{50}$ comparison showed that lemongrass oil had the strongest activity $\left(\mathrm{IC}_{50}<0.00625 \%\right.$ ), followed by geranium bourbon and spearmint oils $\left(\mathrm{IC}_{50}=0.013 \%\right.$ and $0.016 \%$, re-

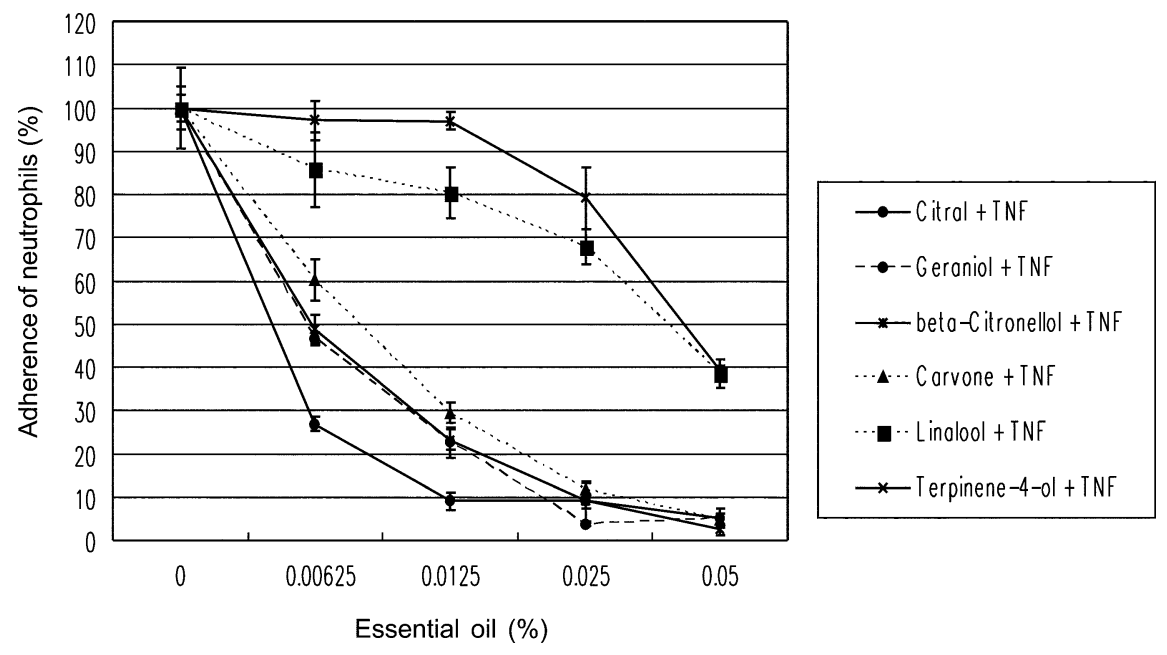

FIG. 2. Effects of terpenoids on TNF--induced neutrophil adherence. See legends to Fig. 1. 

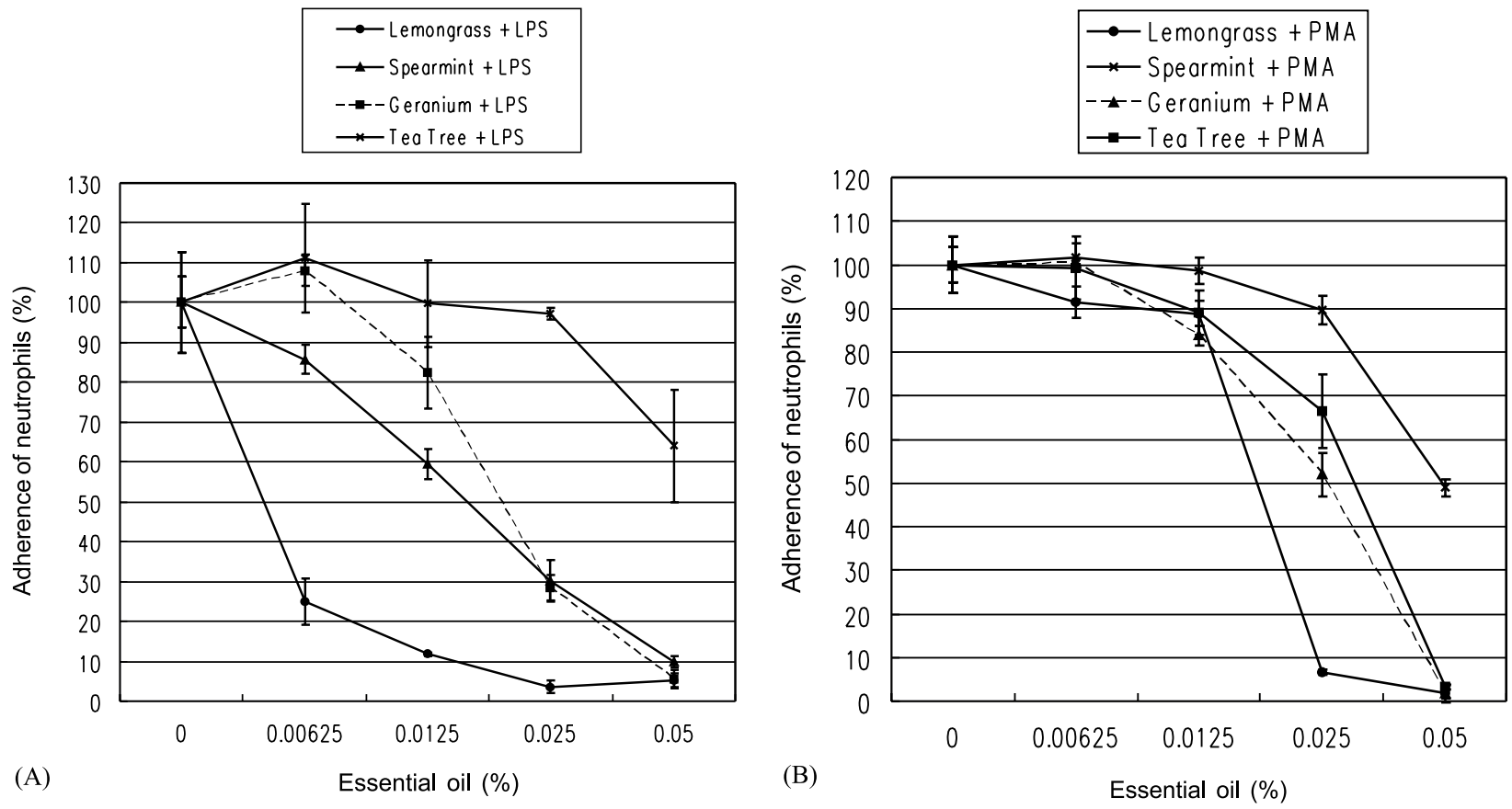

FIG. 3. Effects of essential oils on LPS-induced or PMA-induced neutrophil adherence. Human neutrophils were incubated in the presence of $1 \mu \mathrm{g} / \mathrm{ml}$ of $E$. coli LPS (A) or $0.5 \times 10^{-7} \mathrm{M}$ of PMA (B) and various essential oils for $1 \mathrm{~h}$. See legends to Fig. 1.

spectively) (Table 2 and Fig. 1A,B). As far as we know, this is the first report providing evidence for the suppressive activity of essential oils for neutrophil function. It was reported that the difference in volatility of essential oils affected the results in long-time incubation, ${ }^{16}$ but potent activity of lemongrass, geranium and spearmint oils may not be related with their volatility, since the TNF- $\alpha$-induced neutrophil adherence assay was completed within 1 $\mathrm{h}$ of culture.

TNF- $\alpha$ is one of the major inflammatory cytokines with the capacity for prime activation of the neutrophils for their various functions. ${ }^{8}$ Neutrophil adhesion to a plastic plate is recognized as a parameter representing the priming state of neutrophils ${ }^{17,18}$ in inflammatory responses, which is mediated by major adherent molecules CD11b/CD18. ${ }^{19,20}$ Therefore, these three essential oils, showing suppressive activ-

Table 4. Suppressive activity of essential oils to neutrophil adherence

\begin{tabular}{ll}
\hline Essential oil & $\mathrm{IC}_{50}^{*}(\%)$ \\
\hline Induced by LPS* & \\
Lemongrass & $<0.00625$ \\
Geranium & $0.020 \pm 0.0011$ \\
Spearmint & $0.017 \pm 0.0010$ \\
$\quad$ Tea tree & 0.05 \\
Induced by PMA* & \\
Lemongrass & $0.018 \pm 0.0002$ \\
Geranium & $0.026 \pm 0.0021$ \\
Spearmint & $>0.05$ \\
Tea tree & $0.032 \pm 0.0026$
\end{tabular}

$\mathrm{IC}_{50}$, concentration of essential oils giving $50 \%$ inhibition of neutrophil adherence.

* Data calculated from the results presented in Fig. 3A.

**Data calculated from the results presented in Fig. 3B. ity for TNF- $\alpha$-induced neutrophil adhesion, were suggested to have the capacity to modulate, perhaps negatively, neutrophil function in inflammation.

Usually when essential oils are given to patients by inhalation or body massage for anti-inflammatory use in aromatherapy, they are diluted to $1-3 \%$ by carrier oils. It is well known that essential oils easily penetrate the skin or mucus tissues ${ }^{16}$ and increase the absorption of other drugs. ${ }^{21}$ Although we have no information about the bioavailability of these essential oils in human skin, it is possible to speculate that concentration of these oils may reach about $0.03 \%$, which may show suppression of neutrophil activity in vivo.

Even though juniper, tea tree and lavender oils $\left(\mathrm{IC}_{50}=0.040 \%, 0.033 \%\right.$ and $0.027 \%$, respectively $) \mathrm{did}$ not strongly suppress the neutrophil adhesion (Table 2 and Fig. 1A-D), this does not mean that they cannot suppress the adhering activity of neutrophils in vivo, because popular lavender and tea tree oils are clinically applied by $4 \%$ solution in carrier oils. Of course, the anti-inflammatory activities of lavender and tea tree oils may be explained by other mechanisms, because they also suppress degranulation of mast cells or cytokine production as reported previously. ${ }^{5,7}$

The main constituents of the three essential oils with strong suppressing activities for neurophil adhesion, citral (lemongrass), geraniol and $\beta$-citronellol (geranium), and carvone (spearmint) constitute more than $30 \%$ of each oil and all constituents had strong suppression with $\mathrm{IC}_{50}<0.0083 \%$ (Fig. 2 and Table 3). Citral had the strongest suppressive activity, 
followed by geraniol, $\beta$-citronellol and carvone, which was the same order as that of essential oils (Table 2). This suggests that these main constituents may play a major role in essential oil suppression against neutrophil adhesion. The main constituents of tea tree and lavender oils, terpinen-4-ol and linalool, however, did not suppress neutrophil adhesion strongly. This seems to correspond with the results of each essential oil. From these results we conclude that suppression of the neutrophil adhesion on a plastic plate by essential oils can be explained by the activity of each of the main constituents. Since essential oils contain many constituents, the interaction or interference of each of these constituents to the adherence response should be determined by further investigation.

We examined the essential oil activities against LPSinduced neutrophil adhesion to learn the mechanism underlying the suppressive action of the oils. It is known that LPS activates neutrophil through LPS receptors such as CD14 to induce the adhesive reaction of neutrophil. Again, lemongrass had the strongest activity, followed by geranium bourbon and spearmint oils; tea tree oil did not suppress the adhesion. These results were similar to the results by TNF- $\alpha$ induction. Since lemongrass, geranium and spearmint oils suppressed neutrophil adhesion induced by both TNF- $\alpha$ and LPS, we can speculate that essential oils do not affect TNF- $\alpha$ and LPS, but do affect the neutrophil function to suppress their adhesion. On the contrary, these essential oils did not similarly suppress the PMA-induced neutrophil adhesion (Fig. 3B and Table 4). It is known that PMA activates protein kinase $\mathrm{C}$ in the cell membrane directly, so this indicated that essential oils at low concentration do not have suppressive activities against all types of neutrophil adhesion, but against specific adhesion induced through membrane receptors. Although the mechanism was not elucidated completely, it is possible that essential oils suppress the neutrophil adhesion through signal transduction below the receptor interaction to the ligands TNF and LPS in membrane, because the oils are known to affect the physiological condition of cell membranes. $^{22}$

Modern aromatherapy for inflammatory diseases has been developed primarily based on clinical trials of essential oils by several pioneers, but the scientific research on the physiological role of these oils against inflammatory responses is still at a primitive stage. Elucidation of the pharmacological actions of essential oils against leukocytes in vivo may promote a rational approach to clinical application of these oils as anti-inflammatory substances.
ACKNOWLEDGEMENTS. This work was supported in part by a grant from the Kampo Medicine Research Fund (Tokyo, Japan).

\section{References}

1. Brand C, Grimbaldeston MA, Gamble JR, Finlay-Jones JJ, Hart PH. Tea tree oil reduces the swelling associated with the efferent phase of a contact hypersensitivity response. Inflamm Res 2002; 51: 236-244.

2. Hart PH, Brand C, Carson CF, Riley Tv, Prager RH, Finlay Jones JJ. Terpinen-4-ol, the main component of the essential oil of Melaleuca alternifolia (tea tree oil), suppresses inflammatory mediator production by activated human monocytes. Inflamm Res 2000; 49: 619-626.

3. Syed TA, Qureshi ZA, Ali SM, Ahmad S, Ahmad SA. Treatment of toenail onychomycosis with $2 \%$ butenafine and $5 \%$ Melaleuca alternifolia (tea tree) oil in cream. Trop Med Int Health 1999; 4: 284-287.

4. Kim H-M, Cho S-H. Lavender oil inhibits immediate-type allergic reaction in mice and rats. J Pharm Pharmacol 1999; 51: 221-226.

5. Brand C, Townley SL, Finlay-Jones JJ, Hart PH. Tea tree oil reduces histamine-induced oedema in murine ears. Inflamm Res 2002; 51: $283-$ 289

6. Santos FA, Rao VSN. Mast cell involvement in the rat paw oedema response to 1,8-cineole, the main constituent of eucalyptus and rosemary oils. Eur J Pharmacol 1997; 331: 253-258.

7. Brand C, Ferrante A, Prager RH, et al. The water-soluble components of the essential oil of Melaleuca alternifolia (tea tree oil) suppress the production of superoxide by human monocytes, but not neutrophils, activated in vitro. Inflamm Res 2001; 50: 213-219.

8. McColl SR, Beauseigle D, Gilbert C, Naccache PH. Priming of the human neutrophil respiratory burst by granulocyte-macrophage colony-stimulating factor and tumor necrosis factor-alpha involves regulation at a post-cell surface receptor level. Enhancement of the effect of agents which directly activate G proteins. J Immunol 1990; 145: 3047-3053.

9. Yakuwa $\mathrm{N}$, Inoue $\mathrm{T}$, Watanabe $\mathrm{T}$, Takhashi $\mathrm{K}$, Sendo $\mathrm{F}$. A novel neutrophil adherent test effectively reflects the activated state of neutrophils. Microbiol Immunol 1988; 33: 843-852.

10. Robert T. The Art of Aromatherapy. C.W. Daniel, Essex, UK, 1977.

11. Roger J. L'aromaterapie exactement (Japanese translation). Fragrance Journal 1999, Tokyo, Japan.

12. Rosemary C. Aromatherapy: Essential Oils in Colour. Amberwood Publishing, Kent, UK, 1997.

13. Suzan C. Neal's Yard Remedies: Essential oils. Aurum Press, London, UK, 1996.

14. Ohnishi M, Kimura S, Yamazaki M, Abe S, Yamaguchi H. Characterization of immunological activity of a low toxicity antitumor lipopolysaccharide from Bordetella pertussis. Microbiol Immunol 1994; 38: $733-$ 739 .

15. Tansho T, Okinaga K, Tansho S, Abe S, Yamaguchi H. Suppression of anti-Candida activity of human neutrophils by effect by an amino acid mixture (in Japanese). Jpn J Infect Dis 1996; 70: 463-469.

16. Inoue $S$, Ishihara $H$, Uchida $K$, Yamaguchi H. Preferential percutaneous absorption of monoterpene hydrocarbons and ester of essential oils in mice placed in aroma bath and alteration of compositions of essential oils(in Japanese). Aroma Res 2000; 1: 75-83.

17. Johnson GM, Gomez-Cambronero J. Priming of tyrosine phosphorylation in GM-CSF-stimulated adherent neutrophils. J Leukoc Biol 1995; 57: 692-698.

18. Murata K, Watanabe T, Yamashita T, Gon S, Sendo F. Modulation of rat neutrophil functions by administration of granulocyte colony-stimulating factor. J Leukoc Biol 1995; 57: 250-256.

19. Skoglund $G$, Cotgresve I, Rincon J, Patarroyo $M$, Ingelman-Sundberd $M$. $\mathrm{H} 2 \mathrm{O} 2$ activates CD11b/CD18-dependent cell adhesion. Biochem Biophys Res Commun 1988; 157: 443-449.

20. Schwarts BR, Harlan JM. Sulfhydryl reducing agents promote neutrophil adherence without increasing surface expression of CD11b/CD18 (Mac1 Mo1). Biochem Biophys Res Commun 1989; 165: 51-57.

21. Godwin DA, Michniak BB. Influence of drug lipophilicity on terpenes as transdermal penetration enhancers. Drug Dev Ind Pharm 1999; 25: 905-915.

22. Seeman P. The membrane actions of anesthetics and tranquilizers, Pharmacological Rev 1972; 24: 583-655.

\section{Received 8 August 2003}

Accepted 9 September 2003 


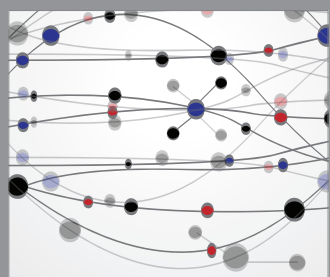

The Scientific World Journal
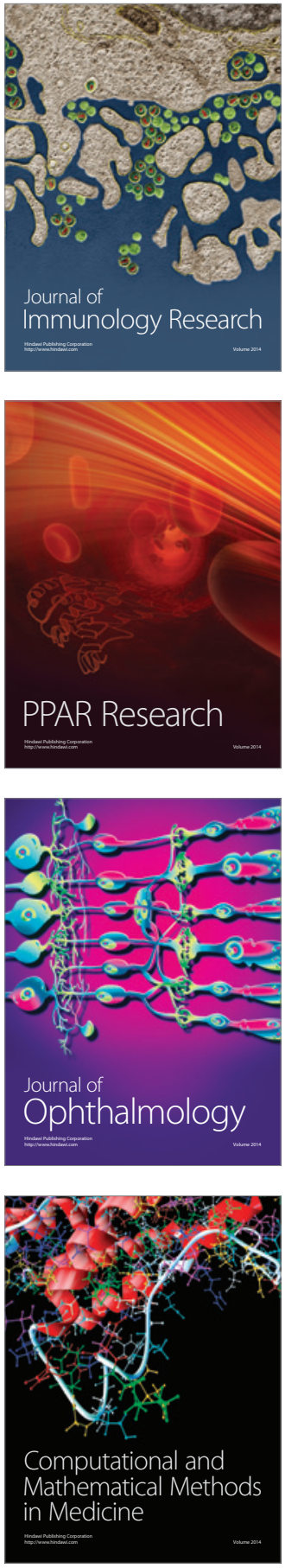

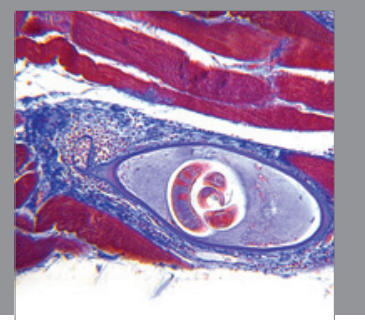

Gastroenterology

Research and Practice
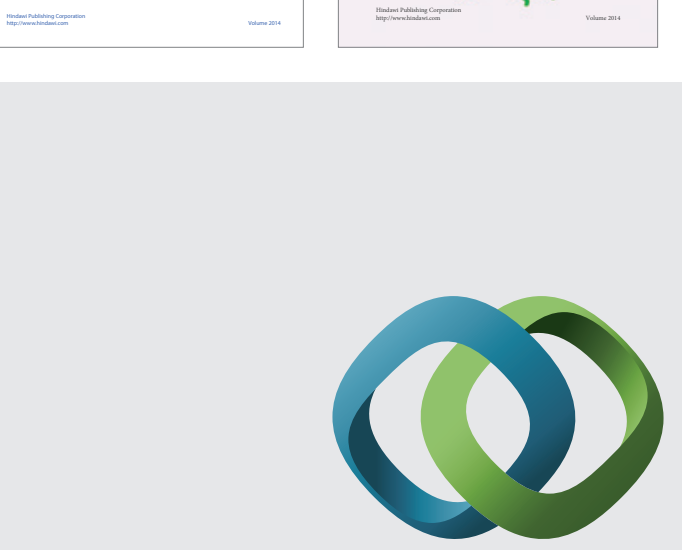

\section{Hindawi}

Submit your manuscripts at

http://www.hindawi.com
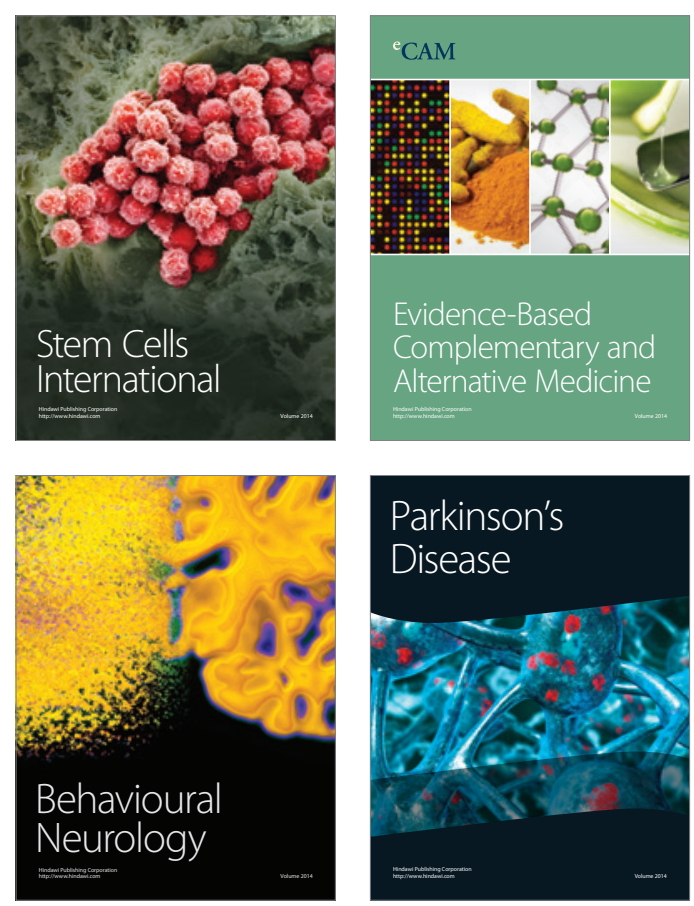

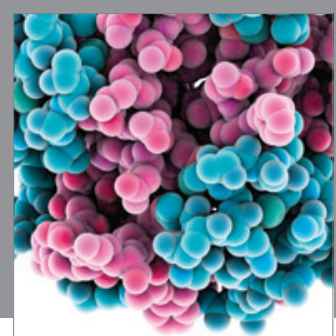

Journal of
Diabetes Research

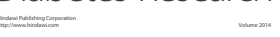

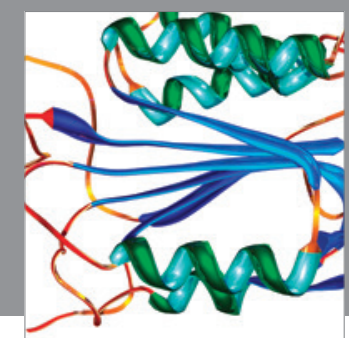

Disease Markers
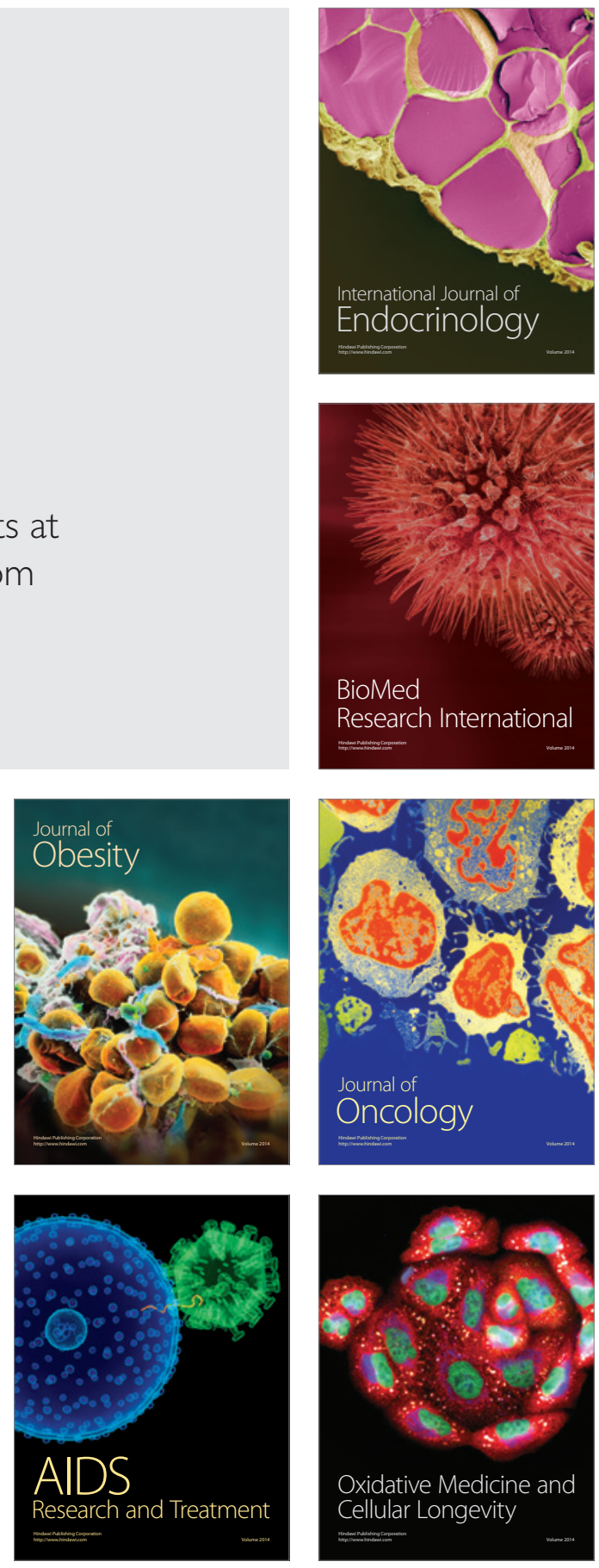